\title{
Vitamin D levels in Indian systemic lupus erythematosus patients: association with disease activity index and interferon alpha
}

Manamita Mandal ${ }^{1 \dagger}$, Rina Tripathy ${ }^{2 \dagger}$, Aditya K Panda ${ }^{3}$, Sarit S Pattanaik ${ }^{1}$, Simanchal Dakua ${ }^{1}$, Anjan Kumar Pradhan ${ }^{4}$, Soumen Chakraborty ${ }^{4}$, Balachandran Ravindran ${ }^{3^{*}}$ and Bidyut K Das ${ }^{1^{*}}$

\begin{abstract}
Introduction: Low levels of vitamin D have been associated with several autoimmune disorders including multiple sclerosis, rheumatoid arthritis, type 1 diabetes and systemic lupus erythematosus (SLE). The major source of vitamin D is sunlight but exposure of SLE patients to UV rays has been shown to exacerbate disease pathology. Studies in various populations have shown an association between low vitamin D levels and higher SLE disease activity.

Methods: We enrolled 129 patients who fulfilled American College of Rheumatology criteria in the study. There were 79 treatment-naïve cases and 50 patients who were under treatment for underlying SLE. There were 100 healthy subjects from similar geographical areas included as controls. Plasma $25-\mathrm{OH}$ vitamin $\mathrm{D}_{3}$ and interferon (IFN)-a levels were quantified by enzyme-linked immunosorbent assay (ELISA). The gene expression level of IFN-a was determined by quantitative real-time reverse transcriptase polymerase chain reaction (RT-PCR).
\end{abstract}

Results: Plasma 25-OH vitamin $D_{3}$ significantly correlated in an inverse manner with systemic lupus erythematosus disease activity index (SLEDAl) scores $(P<0.0001, r=-0.42)$, anti-dsDNA $(P<0.0001, r=-0.39)$, plasma IFN- $a$ $(P<0.0001, r=-0.43)$ and levels of IFN-a gene expression $(P=0.0009, r=-0.45)$. Further, plasma levels of IFN- $a$ positively correlated with gene expression of IFN-a $(P<0.0001, r=0.84)$. Treatment-naïve SLE patients displayed significantly higher plasma levels of IFN-a compared to patients under treatment $(P<0.001)$ and controls $(P<0.001)$.

Conclusions: These results suggest an important role of vitamin $D$ in regulating disease activity in SLE patients and the need to supplement vitamin D in their treatment.

\section{Introduction}

Systemic lupus erythematosus (SLE) is an autoimmune disorder which appears in a group of individuals and which is related to several factors, including environmental and host genetics that contribute to the development of the disease [1]. Patients with SLE develop an immune response against numerous, mostly intracellular self-antigens. This results in formation of immune complexes that get deposited in vascular beds in most organs

\footnotetext{
* Correspondence: ravindran8@gmail.com; bidyutdas@hotmail.com ${ }^{\dagger}$ Equal contributors

${ }^{3}$ Infectious Disease Biology Group, Institute of Life Sciences, Nalco Nagar Road, Bhubaneswar, OD 751023, India

'Department of Medicine, SCB Medical College, Medical College Road, Cuttack, OD 753007, India

Full list of author information is available at the end of the article
}

of the body. Immune complex deposition causes local inflammation and tissue damage that probably amplify the autoimmune response [2]. This has serious consequences on the outcome of the disease.

The importance of vitamin $\mathrm{D}$ in various autoimmune disorders has been reported. Vitamin D deficiency has been associated with multiple sclerosis (MS), rheumatoid arthritis (RA), type 1 diabetes mellitus, inflammatory bowel disease (IBD), mixed connective tissue disease, autoimmune thyroid disease, scleroderma and SLE [3-5]. Vitamin D supplementation improves disease outcome in various animal models of MS [6], RA [7], type 1 diabetes mellitus [8], IBD [9], autoimmune encephalomyelitis [10] and SLE [11]. The role of vitamin D in murine models of SLE has been investigated to a limited degree. Administration of vitamin $\mathrm{D}$ and its synthetic analogs to

\section{Biomed Central}


murine models has resulted in improved dermatological manifestations [11], reduced proteinuria [12] and increased survival $[12,13]$. An earlier report highlighted vitamin $\mathrm{D}_{3}$ insufficiency in two-thirds, and deficiency $(<10 \mathrm{ng} / \mathrm{ml})$ in approximately one-fifth of SLE patients [14]. In addition, serum vitamin $\mathrm{D}_{3}(25-\mathrm{OH})$ levels have been found to correlate inversely with SLE disease activity index (SLEDAI) scores [15-17].

The major source of vitamin D is the conversion of 7 dehydrocholesterol to previtamin $\mathrm{D}_{3}$ in the skin when exposed to solar ultraviolet radiation [18]. Previtamin $\mathrm{D}_{3}$ then gets converted to vitamin $\mathrm{D}_{3}$ (cholecalciferol) through a heat-mediated process in the skin [18]. A lesser amount of vitamin $\mathrm{D}_{3}(25-\mathrm{OH})$ is obtained from foods that supply less than $20 \%$ of the body's requirements. Vitamin $\mathrm{D}_{3}$ undergoes two hydroxylations to achieve its functional form. The first hydroxylation occurs in the liver resulting in 25-hydroxyvitamin $D$ $\left(25(\mathrm{OH}) \mathrm{D}_{3}\right)$ or calcidiol, which is normally quantified for evaluating vitamin D status, and the second hydroxylation takes place in the kidney to its active form 1,25-dihydroxyvitamin D3 $\left(1,25(\mathrm{OH})_{2} \mathrm{D}\right)$ [18]. In addition to the liver and kidney, hydroxylation of vitamin $\mathrm{D}_{3}$ also occurs in the lymph nodes and skin [19].

Several studies worldwide have investigated the role of vitamin $D_{3}$ in the pathogenesis of SLE. However, to date, there have been no reports from an Indian population. Although the prevalence of SLE in India is rare (3 per 100,000 ) [20], the survival rates of these patients (5-year: 70\%; 10-year: 50\%) are low compared to Western cohorts [21,22]. Interestingly, vitamin $\mathrm{D}_{3}$ insufficiency or deficiency appears to be widespread in the Indian subcontinent [23], which makes it important to analyze its role in the background of SLE from an Indian cohort. We have addressed this issue in a tertiary-care, hospitalbased, case-control study, to assess the role of vitamin $D_{3}$ in SLE in a cohort from eastern India.

\section{Methods}

\section{Subjects}

The patients recruited for the study were all inpatients, admitted to the Department of Medicine, under the Clinical Immunology and Rheumatology unit of SCB Medical College, Cuttack, Odisha. As described earlier [24-26], diagnosis of SLE was based on the revised American College of Rheumatology (ACR) classification criteria [27]. After a detailed clinical examination and laboratory investigation, the clinical manifestations were categorized. The clinical profiles of 129 SLE patients are summarized in Table 1. Since, SLE affects women primarily [28], 50 agematched healthy females (medical students: HCA) and 50 healthy subjects from similar geographical areas (HCB) were included as healthy controls (HC). None of the controls reported any history of autoimmune disorder. About
$5 \mathrm{ml}$ blood in EDTA was collected from each participant. The study was approved by the institutional ethics committee of SCB Medical College, Cuttack. Informed consent was obtained from each patient and healthy control.

\section{5-OH vitamin D quantification in plasma}

The plasma levels of 25-OH Vitamin D were quantified by enzyme-linked immunosorbent assay (ELISA) kit (CPC, Euroimmun, Lübeck, Germany) according to the manufacturer's instructions. Vitamin D deficiency was defined as plasma levels of $25-\mathrm{OH}$ vitamin $\mathrm{D}<10 \mathrm{ng} / \mathrm{ml}$ and insufficiency as 10 to $30 \mathrm{ng} / \mathrm{ml}[18]$.

\section{Quantification of plasma interferon alpha}

Plasma levels of interferon (IFN)- $\alpha$ were measured by ELISA kit (Bender MedSystems Inc., Burlingame, CA, USA) according to the manufacturer's protocol.

\section{RNA extraction and reverse transcription}

According to the manufacturer's instructions, total RNA was isolated from $250 \mu \mathrm{l}$ of whole blood by TRIzol LS reagent (Invitrogen, Carlsbad, CA, USA). RNA concentration was determined by spectrophotometry using an Implen NanoPhotometer (Implen, Munich, Germany). To remove any traces of genomic DNA, $1 \mu \mathrm{g}$ of total RNA was then treated with $2 \mathrm{U}$ DNase (Sigma-Aldrich, St Louis, MO, USA) for $30 \mathrm{~min}$ at $37^{\circ} \mathrm{C}$. DNase-treated RNA was reverse transcribed with a hexamer primer using a First Strand cDNA Synthesis kit (Thermo Fisher Scientific, Waltham, MA, USA), according to the manufacturer's instructions. Once the cDNA was synthesized, its fidelity was tested by PCR and stored at $-70^{\circ} \mathrm{C}$.

\section{Real-time PCR assay}

Real-time PCR assay of IFN- $\alpha$ was carried out as described earlier [29]. Briefly, reactions were set up in a total volume of $20 \mu \mathrm{l}$ using $2 \mu \mathrm{l}$ of cDNA, $10 \mu \mathrm{l}$ of MESA GREEN qPCR MasterMix Plus (Eurogentec, Seraing, Belgium) and 10 picomole each of gene-specific primer (IFN- $\alpha$ (sense: 5 ' -TTCCTCCTGYYTGAWGGACAGA-3; antisense: 5'-GATCTCATGATTTCTGCTCTGACA-3'), glyceraldehyde-3 phosphate dehydrogenase (G3PDH) was taken as control (sense: 5'-GGTATCGTGGAAGGACT CATGAC-3'; antisense: 5'-ATGCCAGTGAGCTTCCC GTTCAGC-3')) and performed in the MJ Research DNA Engine Opticon Real-Time Thermal Cycler (MJ Research, Waltham, MA, USA). The cycling conditions were: $95^{\circ} \mathrm{C}$ for $4 \mathrm{~min} ; 35$ cycles of $95^{\circ} \mathrm{C}$ for $30 \mathrm{~s}, 55^{\circ} \mathrm{C}$ for $30 \mathrm{~s}$ and $72^{\circ} \mathrm{C}$ for $30 \mathrm{~s}$ with a single fluorescence measurement; a final elongation step was carried out at $72^{\circ} \mathrm{C}$ for $10 \mathrm{~min}$. Specificity of the PCR products was confirmed by analysis of the dissociation curve. The melting curve program consisted of temperatures between 55 and $95^{\circ} \mathrm{C}$ with a heating rate of $0.1^{\circ} \mathrm{C} / \mathrm{s}$ and a continuous fluorescence measurement. 
Table 1 Clinical characteristics of SLE patients and healthy controls

\begin{tabular}{|c|c|c|c|}
\hline Clinical profiles & SLE $(n=129)$ & \multicolumn{2}{|c|}{ Healthy controls $(n=100)$} \\
\hline Sex (male/female) & $4 / 125$ & \multicolumn{2}{|l|}{$26 / 74$} \\
\hline Age in years (mean $\pm S D$ ) & $28.14 \pm 8.43$ & \multicolumn{2}{|l|}{$31.18 \pm 5.32$} \\
\hline Duration of disease years (mean $\pm S D$ ) & $2.90 \pm 2.66$ & \multicolumn{2}{|l|}{-} \\
\hline SLEDAI scores (mean \pm SD) & $18.36 \pm 6.73$ & \multicolumn{2}{|l|}{-} \\
\hline Photosensitivity rash & $34(26)$ & \multicolumn{2}{|l|}{-} \\
\hline Malar rash & $73(57)$ & \multicolumn{2}{|l|}{-} \\
\hline Discoid rash & $14(11)$ & \multicolumn{2}{|l|}{-} \\
\hline Oral ulcer & $76(59)$ & \multicolumn{2}{|l|}{-} \\
\hline Arthritis & $77(60)$ & \multicolumn{2}{|l|}{-} \\
\hline NPSLE & $11(9)$ & \multicolumn{2}{|l|}{-} \\
\hline Myocarditis & $3(2)$ & \multicolumn{2}{|l|}{-} \\
\hline Serositis & $7(5)$ & \multicolumn{2}{|l|}{-} \\
\hline Nephritis & $46(37)$ & \multicolumn{2}{|l|}{-} \\
\hline Vasculitis & $17(13)$ & \multicolumn{2}{|l|}{-} \\
\hline \multicolumn{4}{|c|}{$\begin{array}{l}\text { Treatment details of patients under therapy at the time of recruitment to the study } \\
(n=50)\end{array}$} \\
\hline & Medicine & Quantity & Number of patient treated (\%) \\
\hline & Prednisolone; mean (range) & 18.99 mg (5-50 mg) & $50(100)$ \\
\hline & Hydroxychloroquine & $6.5 \mathrm{mg} / \mathrm{kg}$ body weight & $50(100)$ \\
\hline & Calcium & $1 \mathrm{~g} /$ day & $50(100)$ \\
\hline & Vitamin $D_{3}$ & 250-500 IU/day & $50(100)$ \\
\hline & Azathioprine & 50-100 mg/day & $4(8)$ \\
\hline & Mycophenolate mofetil & $2 \mathrm{gm} / \mathrm{day}$ & $4(8)$ \\
\hline
\end{tabular}

Note: data are number (\%) of participants unless otherwise specified. SLE, systemic lupus erythematosus; SLEDAl, SLE disease activity index; NPSLE, neuropsychiatric systemic lupus erythematosus.

Additionally, the amplicons' expected size and the absence of nonspecific products were confirmed by analysis of the real-time PCR products in $1 \%$ agarose gel in $1 \times \mathrm{TBE}$, stained with ethidium bromide and visualized under ultraviolet light (expected product size of IFN- $\alpha$ : 375 bp and G3PDH: 187 bp). IFN- $\alpha$ gene expression in each sample was calculated by the $2^{-\Delta \mathrm{Ct}}$ method $(\Delta \mathrm{Ct}=\mathrm{Ct}$ of IFN- $\alpha-$ Ct of GAPDH) [30].

\section{Statistical analysis}

All statistical analysis was performed by GraphPad prism 5.01 (GraphPad Software, San Diego, CA, USA). Distribution of plasma $25-\mathrm{OH}$ vitamin $\mathrm{D}_{3}$ and IFN- $\alpha$ in treatment-naïve SLE patients, controls and treated patients were assessed by D'Agostino-Pearson omnibus normality test. Based on the results of the normality test, the association of $25-\mathrm{OH}$ vitamin $\mathrm{D}_{3}$ and IFN- $\alpha$ with clinical disease was analyzed by analysis of variance (ANOVA) or Kruskal-Wallis test followed by an appropriate post test. Correlation of 25- $\mathrm{OH}$ vitamin $\mathrm{D}_{3}$ with double-stranded (ds)DNA, SLEDAI scores and IFN- $\alpha$ was analyzed by Spearman's correlation test. Further correlation of IFN- $\alpha$ gene expression with plasma IFN- $\alpha$ and $25-\mathrm{OH}$ vitamin
$\mathrm{D}_{3}$ levels was analyzed by Spearman's correlation test. A $P$ value $<0.05$ was considered as significant.

\section{Results}

\section{Clinical characteristics of SLE patients}

One hundred and twenty-nine patients were enrolled in the current study. Baseline characteristics are shown in Table 1. There were 125 (97\%) females and 4 (3\%) males with a mean age (standard deviation) of 28.14 (8.43) years. The mean duration of disease (standard deviation) was 2.90 years (2.66). Out of the 129 SLE patients, 50 patients included in the study were already on treatment for SLE and were also receiving supplements of oral calcium and vitamin $\mathrm{D}_{3}$ at the time of blood collection (Table 1 ). The other 79 patients were treatment-naive cases, undiagnosed earlier and the details of the treatment received for their complaints before hospitalization were not known since the patients had not maintained any records. The clinical profiles of patients were as follows: photosensitivity rash (26\%), malar rash (57\%), discoid rash (11\%), oral ulcer (59\%), arthritis (60\%), neuropsychiatric disease (9\%), myocarditis (2\%), serositis (5\%), nephritis (37\%) and vasculitis (13\%) (Table 1). 


\section{Plasma 25-OH vitamin $\mathrm{D}_{3}$ levels in SLE patients and healthy controls}

Plasma levels of 25-OH vitamin $\mathrm{D}_{3}$ in SLE patients and healthy controls were quantified by ELISA and the results are shown in Figure 1. Patients under vitamin $D_{3}$ supplementation (treated cases) displayed significantly higher levels of $25-\mathrm{OH}$ vitamin $\mathrm{D}_{3}$ compared to treatment-naïve patients $(P<0.001)$ and healthy controls $(P<0.001)$. The levels of plasma 25-OH vitamin $\mathrm{D}_{3}$ in treatment-naïve SLE patients and healthy controls were comparable.

\section{Vitamin $D_{3}$ levels negatively correlated with SLEDAI scores and anti-dsDNA}

Analysis of data in SLE patients revealed a significant negative correlation between plasma $25-\mathrm{OH}$ vitamin $\mathrm{D}_{3}$ levels with SLEDAI scores $(P<0.0001, \mathrm{r}=-0.42)$ (Figure $2 \mathrm{~A}$ ) and anti-dsDNA $(P<0.0001, r=-0.39)$ (Figure $2 B)$. Further, SLE patients were categorized into two groups: treatmentnaïve and those under treatment. As shown in Figure $2 \mathrm{C}$ and $\mathrm{D}$, irrespective of treatment status, the plasma levels of $25-\mathrm{OH}$ vitamin $\mathrm{D}_{3}$ negatively correlated with SLEDAI scores. In addition, a further analysis of the relationship between 25- $\mathrm{OH}$ vitamin $\mathrm{D}_{3}$ and modified SLEDAI scores (eliminating the anti-dsDNA positive score of 2 from SLEDAI), revealed identical results in both the groups (Figures $2 \mathrm{E}$ and $\mathrm{F}$ ). These findings indicate a significant association between $25-\mathrm{OH}$ vitamin $\mathrm{D}_{3}$ and disease activity in SLE.

\section{Correlation between $25-\mathrm{OH}$ vitamin $\mathrm{D}_{3}$ and IFN- $a$}

The role of IFN- $\alpha$ in SLE has been clearly documented and its significant correlation with SLEDAI scores has

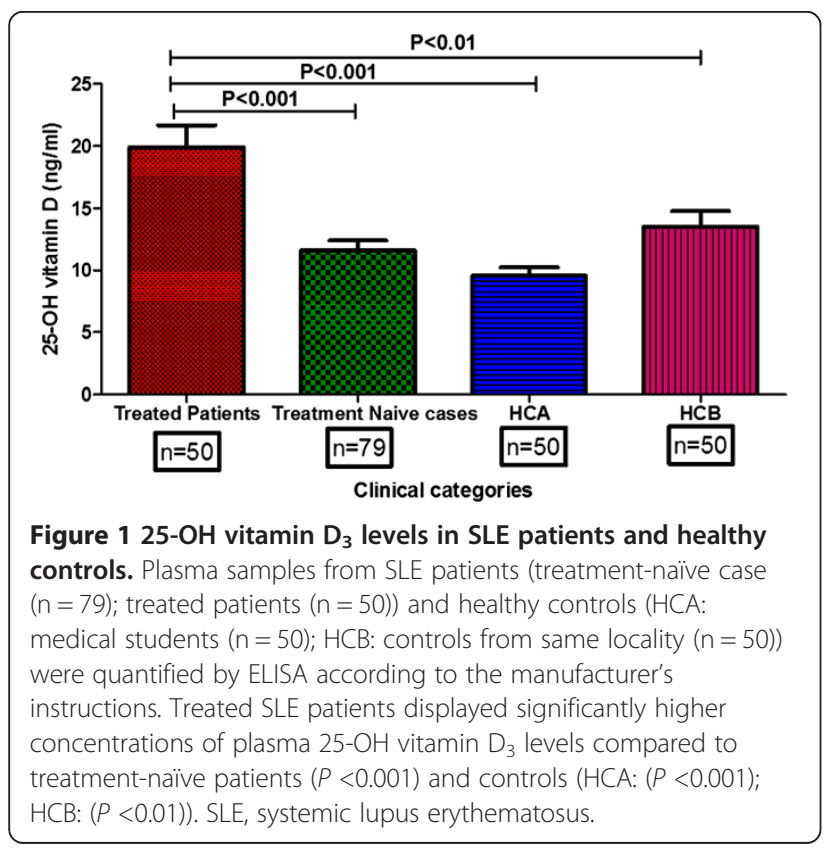

been demonstrated in patients from different populations $[31,32]$. As shown in Figure 3A, a significant negative correlation was observed between $25-\mathrm{OH}$ vitamin $\mathrm{D}_{3}$ levels and plasma IFN- $\alpha(P<0.0001, \mathrm{r}=-0.43)$. Treatment-naïve patients displayed higher levels of plasma IFN- $\alpha$ compared to SLE patients on treatment $(P<0.001)$ and healthy controls $(P<0.001)$ (Figure $3 \mathrm{~B})$ suggesting an important role of IFN- $\alpha$ in modulating disease activity.

\section{Correlation of IFN- $a$ gene expression with plasma IFN- $a$ and $25-\mathrm{OH}$ vitamin $\mathrm{D}_{3}$ levels}

To validate the robustness of IFN- $\alpha$ data, considering that it is an evanescent cytokine, we quantified IFN- $\alpha$ gene expression by RT-PCR in SLE patients $(n=49)$ and correlated the values with plasma levels of IFN- $\alpha$ and $25-\mathrm{OH}$ vitamin $\mathrm{D}_{3}$. As shown in Figure $4 \mathrm{~A}$, a strong positive correlation was observed between IFN- $\alpha$ plasma levels and its gene expression $(P<0.0001, r=84)$. In addition, IFN- $\alpha$ gene expression negatively correlated with plasma $25-\mathrm{OH}$ vitamin $\mathrm{D}_{3}(P=0.0009, \mathrm{r}=-45)$ (Figure 4B).

\section{Association of plasma IFN-a with SLE disease severity}

Role of IFN- $\alpha$ in the pathogenesis of SLE is an important issue that is being investigated [32]. We analyzed the association of IFN- $\alpha$ with disease severity. As shown in Figure $5 \mathrm{~A}$, plasma levels of IFN- $\alpha$ positively correlated with SLEDAI scores $(\mathrm{r}=0.26, P=0.002)$ and patients with severe phenotype displayed significantly higher levels of IFN- $\alpha$ compared to those with mild disease manifestations $(P=0.01)$ (Figure $5 \mathrm{~B})$. However, duration of disease did not correlate with plasma IFN- $\alpha$ levels (data not shown). We also observed a significant inverse correlation between plasma $25-\mathrm{OH}$ vitamin $\mathrm{D}_{3}$ and IFN$\alpha$ levels. This correlation held true while analyzing the association between $25-\mathrm{OH}$ vitamin $\mathrm{D}_{3}$ levels and IFN- $\alpha$ gene expression.

\section{Discussion}

The role of vitamin $D_{3}$ in autoimmune disorders has been the subject of several studies with regard to its importance as an immune regulator [33]. This is the first study from India to demonstrate an association between vitamin $D_{3}$ and SLE, highlighting its significant inverse correlation with SLEDAI scores, anti-dsDNA and IFN- $\alpha$. These are markers of disease activity and IFN- $\alpha$ is closely associated with disease pathogenesis.

Low levels of vitamin $D_{3}$ in SLE patients have been reported compared to healthy controls in different populations [34]. Interestingly, mean plasma levels of $25-\mathrm{OH}$ vitamin D3 were not significantly different among treatment-naïve SLE cases $(11.61 \mathrm{ng} / \mathrm{ml})$, healthy medical students $(9.55 \mathrm{ng} / \mathrm{ml})$ and other healthy controls from same locality $(13.36 \mathrm{ng} / \mathrm{ml})$. Vitamin $\mathrm{D}_{3}$ insufficiency has been 

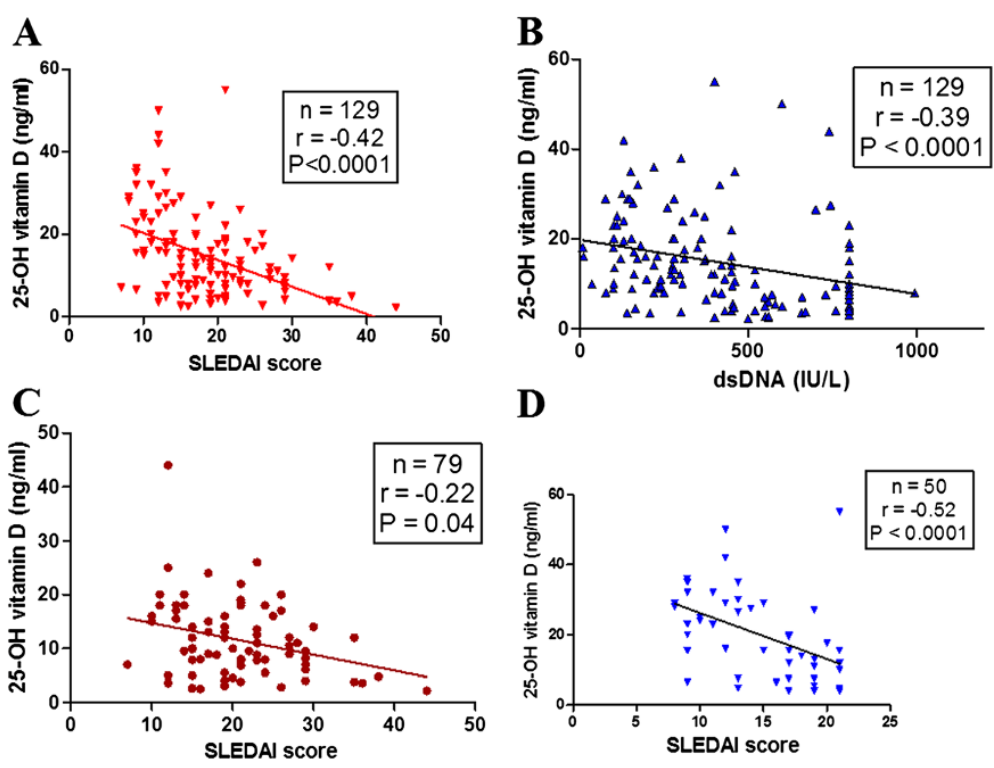

D
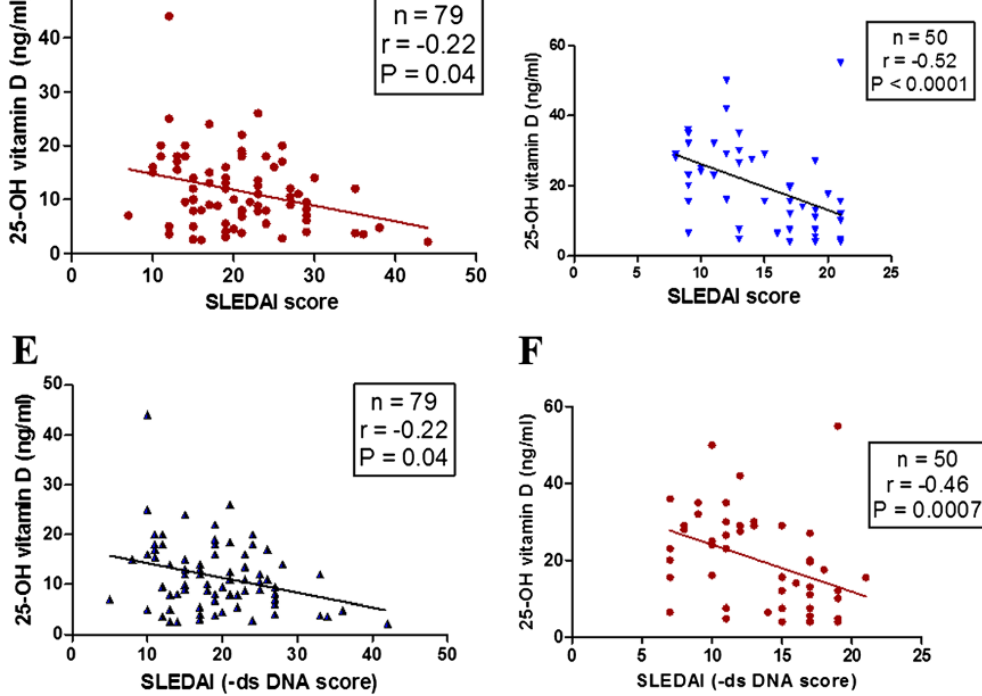

$\mathbf{F}$

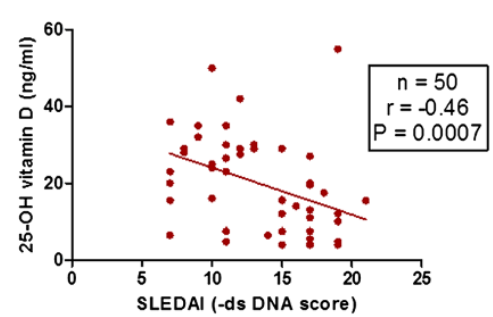

Figure 2 Correlation of $\mathbf{2 5 - O H}$ vitamin $\mathrm{D}_{3}$ with SLEDAI scores and anti-dsDNA levels. Plasma 25-OH vitamin $\mathrm{D}_{3}$ levels of SLE patients correlated negatively with SLEDAI scores (A) and anti-dsDNA (B). SLE patients were categorized into two groups: treatment-naïve cases and patients under treatment. In both groups plasma levels of $25-\mathrm{OH}$ vitamin $\mathrm{D}_{3}$ negatively correlated with SLEDAl scores (C and D). Modified SLEDAI scores (eliminating the anti-dsDNA score of 2) and its correlation with plasma levels of $25-\mathrm{OH}$ vitamin $\mathrm{D}_{3}$ were analyzed. Similar to earlier observations, SLEDAI scores (-anti-dsDNA) negatively correlated with $25-\mathrm{OH}$ vitamin $\mathrm{D}_{3}$ levels in both treatment-naive cases (E) and treated patients (F). Dots represent individual samples. Correlation analysis was performed by Spearman's correlation coefficient. A $P$ value less than 0.05 was considered as significant. SLEDAl, systemic lupus erythematosus disease activity index; SLE, systemic lupus erythematosus; dsDNA, double-stranded DNA.
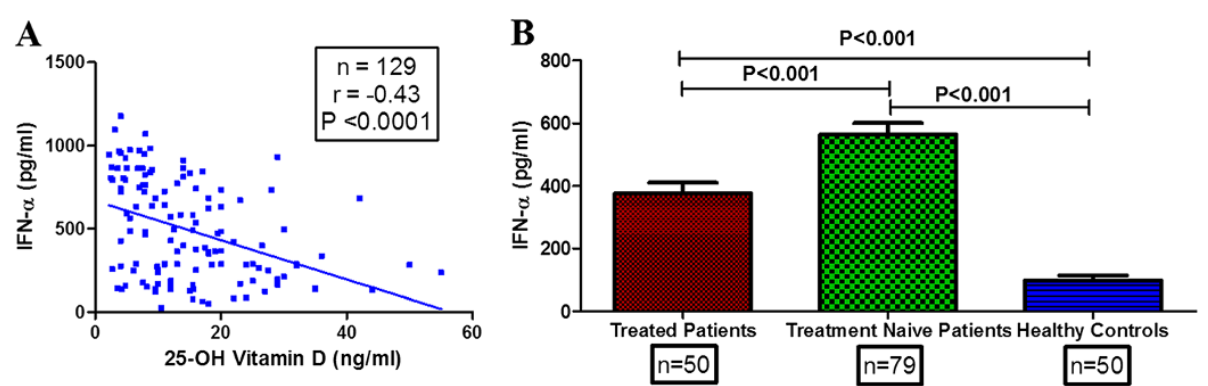

Figure 3 Correlation of plasma IFN- $a$ with $25-\mathrm{OH}$ vitamin $\mathrm{D}_{3}$ and its levels in SLE patients and controls. (A) Plasma 25-OH vitamin $\mathrm{D}_{3}$ levels correlated negatively with IFN-a levels. Dots represent individual samples. Correlation analysis was performed by Spearman's correlation coefficient. (B) Treatment-naïve patients displayed significantly higher levels of IFN-a compared to treated cases and healthy controls. Mean plasma levels of IFN-a in different clinical categories were compared by ANOVA followed by Tukey's multiple comparisons test. A $P$ value less than 0.05 was considered as significant. IFN-a, interferon alpha; SLE, systemic lupus erythematosus. 

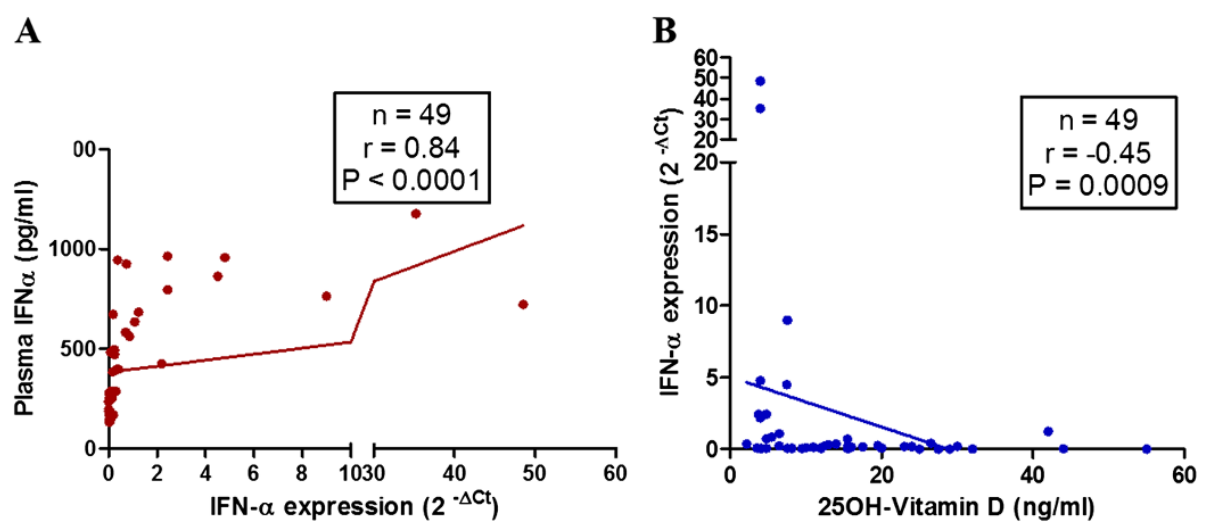

Figure 4 Correlation of IFN-a gene expression with plasma IFN-a levels and $\mathbf{2 5}-\mathbf{O H}$ vitamin $\mathrm{D}_{\mathbf{3}}$. Plasma levels of IFN-a and gene expression levels were quantified by ELISA and RT-PCR respectively. (A) Plasma levels of IFN-a positively correlated with gene expression ( $2^{-\Delta c t}$ ) of IFN-a. (B) IFN-a gene expression $\left(2^{-\Delta c t}\right)$ correlated negatively with plasma levels of $25-\mathrm{OH}$ vitamin $\mathrm{D}_{3}$. Dots represent individual samples. Correlation analysis was performed by Spearman's correlation coefficient. A $P$ value less than 0.05 was considered as significant. IFN-a, interferon alpha.

reported to be widely prevalent in the Indian subcontinent irrespective of the social class [23]. Two groups of healthy controls were analyzed, which included medical students (HCA), who led a lifestyle marked by poor exposure to sunlight and irregular dietary habits, and a group of healthy subjects from the same locality $(\mathrm{HCB})$. Interestingly, $63 \%$ of healthy medical students were deficient and $37 \%$ were insufficient of vitamin $D_{3}$. Furthermore, $94 \%$ of the other groups of healthy controls were either deficient or insufficient of vitamin $\mathrm{D}_{3}$. This was an important observation considering India being a tropical country with lots of sunshine. However, the facts were contrary and several hypotheses have been discussed to explain the discrepancy. Higher melanin concentration in the skin [35], current lifestyle changes, avoidance of sunlight and poor food habits are some of the causes attributed to the widespread prevalence of low vitamin $\mathrm{D}_{3}$ among Indians. Low vitamin $\mathrm{D}_{3}$ may not be cause for development of SLE but persons with low serum levels are likely to suffer from severe disease. The current cross-sectional study does not address the issue of cause and effect relationship between vitamin $\mathrm{D}_{3}$ and SLE.

There are several interesting observations in the current study that points to an important role for vitamin $D_{3}$ in disease modulation. One of them being a significant inverse correlation between vitamin $D_{3}$ and SLEDAI scores and the other association is between vitamin $\mathrm{D}_{3}$ and anti-dsDNA. Association between plasma vitamin $\mathrm{D}_{3}$ and SLEDAI scores has not been uniform across observations: several studies have reported a negative correlation [15-17], while others have found none [36-39].

One of the important functions of vitamin $\mathrm{D}_{3}$ is maintenance of homeostasis of B cells [40]. Low levels of vitamin $D_{3}$ contribute to hyperactivity of $B$ cells and enhanced production of autoantibodies [41]. Furthermore,

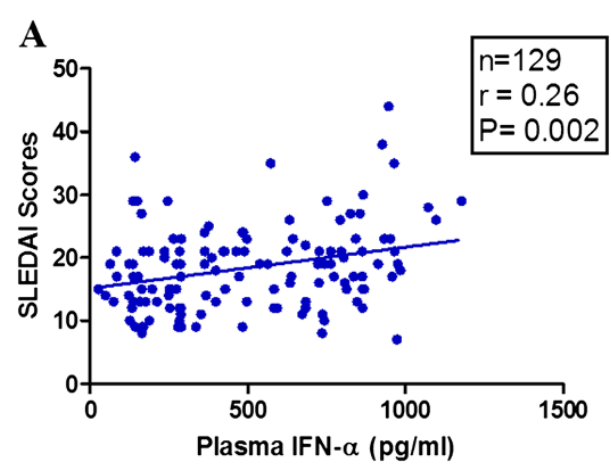

B

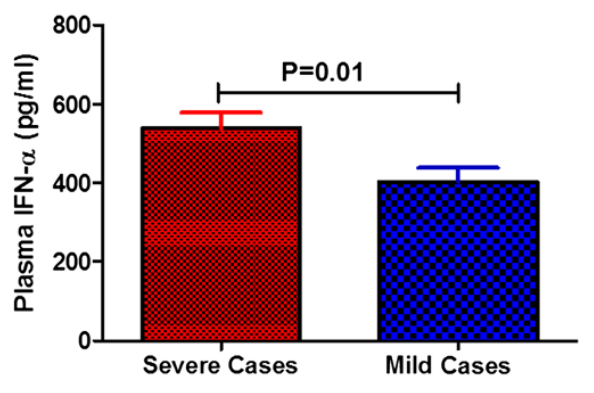

Figure $\mathbf{5}$ Correlation of plasma IFN- $a$ with SLEDAI scores and association with organ involvement. (A) Plasma levels of IFN-a positively correlated with SLEDAI scores. Dots represent individual samples. Correlation analysis was performed by Spearman's correlation coefficient. A $P$ value less than 0.05 was considered as significant. (B) Based on clinical phenotype SLE patients were categorized into two broad groups and plasma levels of IFN-a were compared. Patients with major disease manifestation displayed significantly higher plasma levels of IFN-a than those with minor disease manifestation. Mean plasma levels of IFN-a were compared by unpaired $t$ test and a $P$ value less than 0.05 was taken as significant. IFN-a, interferon alpha; SLEDAl, systemic lupus erythematosus disease activity index; SLE, systemic lupus erythematosus. 
vitamin $\mathrm{D}_{3}$ is known to modulate various immunological pathways [33] and thus could have a defining role in the development, progression and pathogenesis of SLE. Vitamin $D_{3}$ also inhibits differentiation of dendritic cells (DCs) and T-helper cells (CD4+) [42], enhances T regulatory cell proliferation and suppresses release of inflammatory mediators [43], which collectively help in control of autoimmune disorders.

In recent years, the role of interferon in the pathogenesis of lupus has been widely investigated. Higher levels of IFN- $\alpha$ were observed in our SLE patients compared to healthy controls, corroborating earlier observations [32,44-46]. The interferon levels were significantly low in patients under treatment compared to treatmentnaïve cases, supporting its possible role in disease modulation. Furthermore, IFN- $\alpha$ could be a marker of disease activity and low levels in treated patients could indicate response to therapy.

Interestingly, our study revealed a strong negative correlation of vitamin $\mathrm{D}_{3}$ with IFN- $\alpha(P<0.0001, \mathrm{r}=-0.52)$. The robustness of the assay was validated by assessment of IFN- $\alpha$ gene expression, which corroborated with the earlier observations on the association between plasma IFN- $\alpha$ and vitamin $D_{3}$. There are no reports in the literature assessing the association between IFN- $\alpha$ and vitamin $\mathrm{D}_{3}$.

In active SLE overexpression of interferon-inducible genes (IFN signature) has been reported [47]. The major source of IFN- $\alpha$ in SLE patients are activated DCs. Maturation/activation of DCs and production of IFN- $\alpha$ has been observed to be inhibited by vitamin $\mathrm{D}$ in in vitro studies $[48,49]$. A direct role for vitamin $\mathrm{D}_{3}$ in modulating lupus activity has been demonstrated in animal models [11-13]. Our observations, although cross-sectional, and studies on experimental models, provide evidence for a disease-modulating role for vitamin $\mathrm{D}_{3}$, which could be a promising therapeutic adjunct in the treatment of SLE. In view of the limited number of drugs available for the treatment of lupus and the low cost of vitamin $\mathrm{D}_{3}$ therapy, there is a strong case for its use routinely.

\section{Conclusions}

To conclude, vitamin D deficiency is prevalent among healthy Indians as well as among SLE patients. The significant inverse correlation of vitamin $\mathrm{D}_{3}$ with SLEDAI scores, anti-dsDNA and IFN- $\alpha$ highlights its immunemodulatory role contributing to disease outcome. Although the present study indicates a necessity for vitamin $\mathrm{D}_{3}$ supplementation in the management of SLE patients, larger randomized controlled trials would be necessary to define the daily requirement and optimum blood levels of vitamin $\mathrm{D}_{3}$ that are effective in influencing disease outcome.

\section{Abbreviations}

ACR: American College of Rheumatology; C3: complement component 3; C4: complement component 4; DCs: dendritic cells; dsDNA: double-stranded DNA; ELISA: enzyme-linked immunosorbent assay; HC: healthy controls; IBD: inflammatory bowel disease; IFN-a: interferon alpha; MS: multiple sclerosis; NPSLE: neuropsychiatric systemic lupus erythematosus; RT-PCR: realtime polymerase chain reaction; RA: rheumatoid arthritis; SLE: systemic lupus erythematosus; SLEDAl: systemic lupus erythematosus disease activity index.

\section{Competing interests}

The authors declare that they have no competing interests.

\section{Authors' contributions}

MM, SD and SSP were involved in samples collection, data management and clinical categorization of samples. AdKP carried out quantification of IFN-a by ELISA, real-time PCR, data interpretation and wrote the first draft of the manuscript. AnKP and SC quantified IFN-a gene expression and interpreted the results. RT performed all routine tests including measurement of vitamin D. RT, BR and BKD made a contribution in the design, data interpretation, work supervision and critically revising the manuscript. All authors read and approved the manuscript.

\section{Acknowledgements}

The work was partly supported by intramural grants from the Department of Biotechnology, Government of India to the Institute of Life Sciences, Bhubaneswar. We would like to thank all patients and controls included in this study. We also thank to Mr. Subrat K. Mohanty for collection of blood from patients and healthy controls.

\section{Author details}

'Department of Medicine, SCB Medical College, Medical College Road, Cuttack, OD 753007, India. ${ }^{2}$ Department of Biochemistry, SCB Medical College, Medical College Road, Cuttack, OD 753007, India. Infectious Disease Biology Group, Institute of Life Sciences, Nalco Nagar Road, Bhubaneswar, OD 751023, India. ${ }^{4}$ Department of Gene Function and Regulation, Institute of Life Sciences, Nalco Nagar Road, Bhubaneswar, OD 751023, India.

Received: 12 May 2013 Accepted: 24 January 2014

Published: 10 February 2014

\section{References}

1. Crispin JC, Liossis SN, Kis-Toth K, Lieberman LA, Kyttaris VC, Juang YT, Tsokos GC: Pathogenesis of human systemic lupus erythematosus: recent advances. Trends Mol Med 2010, 16:47-57.

2. Tsokos GC: Systemic lupus erythematosus. N Engl J Med 2011, 365:2110-2121.

3. Gatenby P, Lucas R, Swaminathan A: Vitamin D deficiency and risk for rheumatic diseases: an update. Curr Opin Rheumatol 2013, 25:184-191.

4. Pludowski P, Holick MF, Pilz S, Wagner CL, Hollis BW, Grant WB, Shoenfeld Y, Lerchbaum E, Llewellyn DJ, Kienreich K, Soni M: Vitamin D effects on musculoskeletal health, immunity, autoimmunity, cardiovascular disease, cancer, fertility, pregnancy, dementia and mortality-a review of recent evidence. Autoimmun Rev 2013, 12:976-989.

5. Yang CY, Leung PS, Adamopoulos IE, Gershwin ME: The implication of vitamin $D$ and autoimmunity: a comprehensive review. Clin Rev Allergy Immunol 2013, 45:217-226.

6. Munger KL, Levin LI, Hollis BW, Howard NS, Ascherio A: Serum 25-hydroxyvitamin D levels and risk of multiple sclerosis. JAMA 2006, 296:2832-2838.

7. Cantorna MT, Hayes CE, DeLuca HF: 1,25-Dihydroxycholecalciferol inhibits the progression of arthritis in murine models of human arthritis. J Nutr 1998, 128:68-72.

8. Mathieu C, Waer M, Laureys J, Rutgeerts O, Bouillon R: Prevention of autoimmune diabetes in NOD mice by 1,25 dihydroxyvitamin D3. Diabetologia 1994, 37:552-558.

9. Cantorna MT, Munsick C, Bemiss C, Mahon BD: 1,25-Dihydroxycholecalciferol prevents and ameliorates symptoms of experimental murine inflammatory bowel disease. J Nutr 2000, 130:2648-2652.

10. Lemire JM, Archer DC: 1,25-dihydroxyvitamin D3 prevents the in vivo induction of murine experimental autoimmune encephalomyelitis. J Clin Invest 1991, 87:1103-1107. 
11. Lemire JM, Ince A, Takashima M: 1,25-Dihydroxyvitamin D3 attenuates the expression of experimental murine lupus of MRL/I mice. Autoimmunity 1992, 12:143-148.

12. Abe J, Nakamura K, Takita Y, Nakano T, Irie H, Nishii Y: Prevention of immunological disorders in MRL/I mice by a new synthetic analogue of vitamin D3: 22-oxa-1 alpha,25-dihydroxyvitamin D3. J Nutr Sci Vitaminol 1990, 36:21-31.

13. Vaisberg MW, Kaneno R, Franco MF, Mendes NF: Influence of cholecalciferol (vitamin D3) on the course of experimental systemic lupus erythematosus in F1 (NZBxW) mice. J Clin Lab Anal 2000, 14:91-96.

14. Kamen DL, Cooper GS, Bouali H, Shaftman SR, Hollis BW, Gilkeson GS: Vitamin D deficiency in systemic lupus erythematosus. Autoimmun Rev 2006, 5:114-117.

15. Borba VZ, Vieira JG, Kasamatsu T, Radominski SC, Sato El, Lazaretti-Castro M: Vitamin D deficiency in patients with active systemic lupus erythematosus. Osteoporos Int 2009, 20:427-433.

16. Hamza RT, Awwad KS, Ali MK, Hamed Al: Reduced serum concentrations of 25-hydroxy vitamin D in Egyptian patients with systemic lupus erythematosus: relation to disease activity. Med Sci Monit 2011, 17:CR711-CR718.

17. Vacca A, Cormier C, Piras M, Mathieu A, Kahan A, Allanore Y: Vitamin D deficiency and insufficiency in 2 independent cohorts of patients with systemic sclerosis. J Rheumatol 2009, 36:1924-1929.

18. Holick MF: Vitamin D deficiency. N Engl J Med 2007, 357:266-281.

19. Hewison M, Zehnder D, Bland R, Stewart PM: 1alpha-hydroxylase and the action of vitamin D. J Mol Endocrinol 2000, 25:141-148.

20. Malaviya AN, Singh RR, Singh YN, Kapoor SK, Kumar A: Prevalence of systemic lupus erythematosus in India. Lupus 1993, 2:115-118.

21. Kumar A, Malaviya AN, Singh RR, Singh YN, Adya CM, Kakkar R: Survival in patients with systemic lupus erythematosus in India. Rheumatol Int 1992, 12:107-109.

22. Murali R, Jeyaseelan L, Rajaratnam S, John L, Ganesh A: Systemic lupus erythematosus in Indian patients: prognosis, survival and life expectancy. Natl Med J India 1997, 10:159-164

23. Vijay J, Kapil U: Vitamin d deficiency and its health consequences - a review. Indian J. Community Health 2012, 24:232-236.

24. Panda AK, Parida JR, Tripathy R, Pattanaik SS, Ravindran B, Das BK: Low producer MBL genotypes are associated with susceptibility to systemic lupus erythematosus in Odisha, India. Hum Immunol 2013, 74:114-119.

25. Panda AK, Parida JR, Tripathy R, Pattanaik SS, Ravindran B, Das BK: Mannose binding lectin: a biomarker of systemic lupus erythematosus disease activity. Arthritis Res Ther 2012, 14:R218.

26. Panda AK, Pattanaik SS, Tripathy R, Das BK: TLR-9 promoter polymorphisms ( $\mathrm{T}-1237 \mathrm{C}$ and $\mathrm{T}-1486 \mathrm{C}$ ) are not associated with systemic lupus erythematosus: A case control study and meta-analysis. Hum Immunol 2013, 74:1672-1678.

27. Hochberg MC: Updating the American College of Rheumatology revised criteria for the classification of systemic lupus erythematosus. Arthritis Rheum 1997, 40:1725.

28. Danchenko N, Satia JA, Anthony MS: Epidemiology of systemic lupus erythematosus: a comparison of worldwide disease burden. Lupus 2006, 15:308-318.

29. Palmer P, Tovey MG, Raschilas F, Brassart L, Meritet JF, Porcher R, Lebon P: Type I interferon subtypes produced by human peripheral mononuclear cells from one normal donor stimulated by viral and non-viral inducing factors. Eur Cytokine Netw 2007, 18:108-114.

30. Livak KJ, Schmittgen TD: Analysis of relative gene expression data using real-time quantitative PCR and the 2(-Delta Delta $C(T)$ ) method. Methods 2001, 25:402-408.

31. Ronnblom L: Potential role of IFN alpha in adult lupus. Arthritis Res Ther 2010, 12:S3

32. Niewold TB, Clark DN, Salloum R, Poole BD: Interferon alpha in systemic lupus erythematosus. J Biomed Biotechnol 2010, 2010:948364.

33. Bikle DD: Vitamin D and immune function: understanding common pathways. Curr Osteoporos Rep 2009, 7:58-63.

34. Cutolo M, Otsa K: Review: vitamin D, immunity and lupus. Lupus 2008, 17:6-10.

35. Clemens TL, Adams JS, Henderson SL, Holick MF: Increased skin pigment reduces the capacity of skin to synthesise vitamin D3. Lancet 1982, $1: 74-76$.

36. Ruiz-Irastorza G, Egurbide MV, Olivares N, Martinez-Berriotxoa A, Aguirre C: Vitamin D deficiency in systemic lupus erythematosus: prevalence, predictors and clinical consequences. Rheumatology (Oxford) 2008, 47:920-923.

37. Muller K, Kriegbaum NJ, Baslund B, Sorensen OH, Thymann M, Bentzen K Vitamin D3 metabolism in patients with rheumatic diseases: low serum levels of 25-hydroxyvitamin D3 in patients with systemic lupus erythematosus. Clin Rheumatol 1995, 14:397-400.

38. Chen TC, Chimeh F, Lu Z, Mathieu J, Person KS, Zhang A, Kohn N, Martinello S, Berkowitz R, Holick MF: Factors that influence the cutaneous synthesis and dietary sources of vitamin D. Arch Biochem Biophys 2007, 460:213-217.

39. Toloza SM, Cole DE, Gladman DD, Ibanez D, Urowitz MB: Vitamin D insufficiency in a large female SLE cohort. Lupus 2010, 19:13-19.

40. Terrier B, Derian N, Schoindre Y, Chaara W, Geri G, Zahr N, Mariampillai K, Rosenzwajg M, Carpentier W, Musset L, Piette JC, Six A, Klatzmann D, Saadoun D, Patrice C, Costedoat-Chalumeau N: Restoration of regulatory and effector T cell balance and B cell homeostasis in systemic lupus erythematosus patients through vitamin D supplementation. Arthritis Res Ther 2012, 14:R221.

41. Ritterhouse LL, Crowe SR, Niewold TB, Kamen DL, Macwana SR, Roberts VC, Dedeke AB, Harley JB, Scofield RH, Guthridge JM, James JA: Vitamin D deficiency is associated with an increased autoimmune response in healthy individuals and in patients with systemic lupus erythematosus. Ann Rheum Dis 2011, 70:1569-1574.

42. Cantorna MT, Mahon BD: Mounting evidence for vitamin D as an environmental factor affecting autoimmune disease prevalence. Exp Biol Med (Maywood) 2004, 229:1136-1142.

43. Chambers ES, Hawrylowicz CM: The impact of vitamin D on regulatory $T$ cells. Curr Allergy Asthma Rep 2011, 11:29-36.

44. Kirou KA, Lee C, George S, Louca K, Peterson MG, Crow MK: Activation of the interferon-alpha pathway identifies a subgroup of systemic lupus erythematosus patients with distinct serologic features and active disease. Arthritis Rheum 2005, 52:1491-1503.

45. Dall'era MC, Cardarelli PM, Preston BT, Witte A, Davis JC Jr: Type I interferon correlates with serological and clinical manifestations of SLE. Ann Rheum Dis 2005, 64:1692-1697.

46. Feng $X$, Wu H, Grossman JM, Hanvivadhanakul P, FitzGerald JD, Park GS, Dong $X$ Chen W, Kim MH, Weng HH, Furst DE, Gorn A, McMahon M, Taylor M, Brahn E, Hahn BH, Tsao BP: Association of increased interferon-inducible gene expression with disease activity and lupus nephritis in patients with systemic lupus erythematosus. Arthritis Rheum 2006, 54:2951-2962.

47. Bennett L, Palucka AK, Arce E, Cantrell V, Borvak J, Banchereau J, Pascual V: Interferon and granulopoiesis signatures in systemic lupus erythematosus blood. J Exp Med 2003, 197:711-723.

48. Reichel H, Koeffler HP, Tobler A, Norman AW: 1 alpha,25-dihydroxyvitamin D3 inhibits gamma-interferon synthesis by normal human peripheral blood lymphocytes. Proc Natl Acad Sci U S A 1987, 84:3385-3389.

49. Griffin MD, Lutz WH, Phan VA, Bachman LA, McKean DJ, Kumar R: Potent inhibition of dendritic cell differentiation and maturation by vitamin $D$ analogs. Biochem Biophys Res Commun 2000, 270:701-708.

\section{doi:10.1186/ar4479}

Cite this article as: Mandal et al:: Vitamin D levels in Indian systemic lupus erythematosus patients: association with disease activity index and interferon alpha. Arthritis Research \& Therapy 2014 16:R49.

\section{Submit your next manuscript to BioMed Central and take full advantage of:}

- Convenient online submission

- Thorough peer review

- No space constraints or color figure charges

- Immediate publication on acceptance

- Inclusion in PubMed, CAS, Scopus and Google Scholar

- Research which is freely available for redistribution 